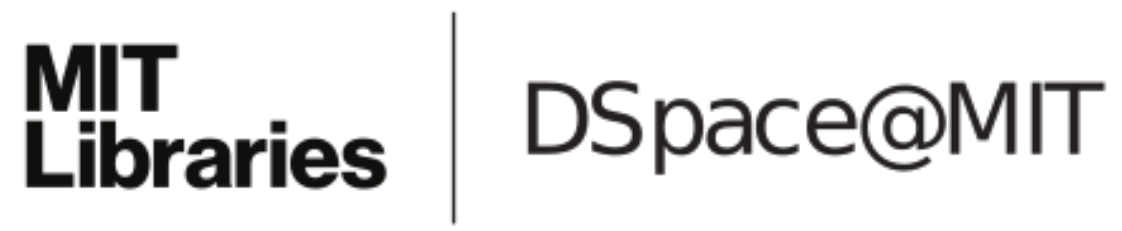

\author{
MIT Open Access Articles
}

Teaching about complex systems is no simple matter: building effective professional development for computer-supported complex systems instruction

The MIT Faculty has made this article openly available. Please share how this access benefits you. Your story matters.

Citation: Yoon, Susan A. et al. "Teaching about Complex Systems Is No Simple Matter: Building Effective Professional Development for Computer-Supported Complex Systems Instruction." Instructional Science (2016): n. pag.

As Published: http://dx.doi.org/10.1007/s11251-016-9388-7

Publisher: Springer Netherlands

Persistent URL: http://hdl.handle.net/1721.1/106838

Version: Author's final manuscript: final author's manuscript post peer review, without publisher's formatting or copy editing

Terms of use: Creative Commons Attribution-Noncommercial-Share Alike 


\title{
Teaching about complex systems is no simple matter: building effective professional development for computer-supported complex systems instruction
}

\author{
Susan A. Yoon ${ }^{1} \cdot$ Emma Anderson $^{1} \cdot$ Jessica Koehler-Yom $^{1} \cdot$ \\ Chad Evans $^{1} \cdot$ Miyoung Park $^{1} \cdot$ Josh Sheldon $^{2}$ • \\ Ilana Schoenfeld ${ }^{2} \cdot$ Daniel Wendel $^{2} \cdot$ Hal Scheintaub $^{2}$. \\ Eric Klopfer ${ }^{2}$
}

Received: 16 April 2015/Accepted: 30 August 2016

(C) Springer Science+Business Media Dordrecht 2016

\begin{abstract}
The recent next generation science standards in the United States have emphasized learning about complex systems as a core feature of science learning. Over the past 15 years, a number of educational tools and theories have been investigated to help students learn about complex systems; but surprisingly, little research has been devoted to identifying the supports that teachers need to teach about complex systems in the classroom. In this paper, we aim to address this gap in the literature. We describe a 2-year professional development study in which we gathered data on teachers' abilities and perceptions regarding the delivery of computer-supported complex systems curricula. We present results across the 2 years of the project and demonstrate the need for particular instructional supports to improve implementation efforts, including providing differentiated opportunities to build expertise and addressing teacher beliefs about whether computational-model construction belongs in the science classroom. Results from students' classroom experiences and learning over the 2 years are offered to further illustrate the impact of these instructional supports.
\end{abstract}

Keywords Complex systems · Computer-supported instruction · Professional development $\cdot$ Science education

Education, in its truest sense, is not about 'a saleable skill set.' It's about freedom, from inherited prejudice and argument by authority. This is the deepest contribution of the modeling enterprise. It enforces habits of mind essential to freedom.

-Epstein (2008).

Susan A. Yoon

yoonsa@gse.upenn.edu

1 University of Pennsylvania, 3700 Walnut Street, Philadelphia, PA 19104, USA

2 Massachusetts Institute of Technology, 77 Massachusetts Ave, Cambridge, MA 02139, USA 
Complex systems are highlighted as an essential feature of science teaching and learning in the next generation science standards (NGSS). Beyond the classroom, the National Academies have stressed the need to investigate the fundamental science behind complex systems in various domains of scientific study (The National Academies 2009). Although a good deal of educational research over the last 15 years has concentrated on developing students' understanding of complex systems, surprisingly few studies have focused on identifying supports that will help teachers provide instruction on these systems. Building on models for best practices in science teacher professional development (PD), in this study we examine essential variables for teachers to successfully enact computer-supported complex systems instruction. Data are collected from a 2-year curriculum and instruction implementation project in high school biology classrooms, in which teachers received ongoing PD training. Using a mixed-methods, longitudinal approach to analyze teacher and student data, we investigated the following research questions: 1) What PD supports do teachers need to teach about complex systems effectively? and 2) To what extent do students learn and experience changes in classroom learning activities as a result of effective PD?

\section{Teaching and learning about complex systems in science education: motivations and theoretical considerations}

Systems can be found in structures and behaviors in all aspects of our world. At the micro scale, the emergence of a human form from a single fertilized egg happens through multiple interacting systems. At the macro scale, complex systems come in the form of businesses, cities, animal populations, and ecosystems. Although complex systems vary in their physical components, a common feature of all such systems is the presence of multiple, interconnected elements that behave in nonlinear ways. Through interactions in feedback loops, the parts form a collective network of relationships that exhibit emergent properties that are often not observable at subsystem levels. Systems also evolve through perturbations, random mutations, and exogenous variables that can cause the network to self-organize in unpredictable ways. To understand how complex systems function, respond to perturbations, adapt, and self-organize, scientists study the dynamical processes that fuel them.

Given the dynamic and continually changing nature of complex systems, and that they exhibit different behaviors and structures at multiple scales, they are best understood through computer-based models that simulate system activities. In science education, simulations provide learning affordances that can scaffold meaning making in important ways (Honey and Hilton 2011; Smetana and Bell 2012). Simulations depict changes over time and represent a continuous flow of motion; this is in contrast to static images, which depict only instantaneous snapshots of the phenomenon or process (Schnotz and Lowe 2008). In a comprehensive review of the empirical research on computer simulations in science instruction and learning, Smetana and Bell (2012) found that simulations can be effective for developing science content knowledge and process skills as well as for supporting conceptual change. They also found that these positive learning effects happen when simulations are used to supplement, rather than replace, instruction; when student learning is supported through high-quality scaffolds orchestrated by the teacher; and when opportunities for students to experience cognitive dissonance are built into the learning 
activities. Thus, it is clear that the teacher's role in helping students learn with computer simulations is essential to optimize the learning benefits.

\section{Research on complex systems computer simulations and supports}

A number of computational tools, curricula, and theoretical approaches have emerged to support learning about complex systems, which include both content and processes. Software applications and associated curricula-including StarLogo, NetLogo, Model-It, Biologica, hypermedia systems, and handheld Participatory Simulations (Colella et al. 2001; Gobert 2005; Liu and Hmelo-Silver 2009; Klopfer et al. 2005; Resnick 1994; Soloway and Pryor 1997; Wilensky and Reisman 2006; Yoon et al. 2013)—have been created to teach school-age students about systems and models. Agent-based programs like StarLogo and NetLogo give users information about individual behaviors that produce population-level outcomes. Other long-standing science curriculum projects have embedded computer simulations that model complex systems to illustrate scientific phenomena in support of developing inquiry skills (Linn et al. 2002; Slotta and Linn 2009) and scientific explanations through scientific practices (Reiser et al. 2001; Sandoval and Millwood 2005; Tabak and Reiser 2008). Theoretical frameworks such as structure, behavior, and function (Liu and Hmelo-Silver 2009); complex systems component beliefs (Yoon 2008, 2011; Jacobson 2001; Jacobson et al. 2011); and midlevel reasoning (Levy and Wilensky 2008) have also been used in conjunction with computer simulations to develop theories about what students know (content) and how they learn (processes) about complex systems. Finally, some researchers have focused on investigating what people at different ages or in different populations know about complex systems through computer simulations; among the populations studied were kindergarten students (Danish 2014), undergraduates (Jacobson et al. 2011), and teachers (Hmelo-Silver et al. 2007). The general consensus from this collective research is that computer simulations can help students develop deeper understanding of how complex systems operate and evolve, the kinds of variables and structures the comprise complex systems, and that complex systems can be learned at all different levels of the educational pipeline.

\section{Research on teacher's understanding of complex systems}

Despite relatively robust research on the development and application of computational tools, of the 65 empirical studies on this topic that have appeared in the last 15 years, only a handful have studied teacher understanding of complex systems. Even fewer have studied teachers in practice. Through clinical interviews and participation in university courses, researchers have found that preservice students do not have a developed understanding of core system characteristics such as ecological levels and the nestedness of system parts (Brown and Schwartz 2009). They also have a weak understanding of system behaviors and functions when compared to their understanding of system structures (Hmelo-Silver and Pfeffer 2004; Liu and Hmelo-Silver 2009). Research on in-service teachers, again through clinical interviews, has shown similar weaknesses in complex systems understanding. Booth-Sweeney and Sterman (2007) found that a majority of their teacher population was unable to adequately describe feedback and stock and flow processes.

Although some studies acknowledge the important role that teachers play in constructing successful classroom learning experiences (e.g., Perkins and Grotzer 2005), we found only two research studies that explicitly focused on working with teachers in the classroom context. The first such study, by Randler and Bogner (2009), looked only at the 
teacher's effect on student learning outcomes rather than investigating teacher understanding. The researchers found that teachers had a significant influence on the learning outcome irrespective of the treatment or control condition but that some teachers coped better with traditional teaching methods. In our own study (Yoon and Klopfer 2006) we looked at the supports teachers needed in carrying out computer-supported complex systems curricula in their classrooms. Teachers' lack of comfort with computer programming and pedagogical expertise, and the desire to connect with other practicing teachers, necessitated modifications in the PD activities we offered, which led to improved project implementation.

Collectively, these studies show that teachers do not demonstrate a strong command of complex systems content and, importantly, when given a choice, tend to fare better with traditional teaching over complex systems instruction. This review also clearly highlights the need for PD opportunities for teachers as well as more studies that investigate how teachers apply their understanding in classroom contexts and what supports they need to enact complex systems curricula and instruction.

\section{Additional considerations for teacher professional development}

Fortunately, we can consult a robust body of research that identifies issues and practices to build from when considering supports needed for teacher PD in the domain of science and technology education. Through a large-scale national survey of science and mathematics teachers, Desimone and colleagues revealed five essential characteristics of high quality PD. These include a focus on subject matter content; active learning opportunities; coherence with teachers' knowledge, beliefs, and professional demands; at least $20 \mathrm{~h}$ in duration and spread over a semester; and collective participation of teachers (Desimone 2009; Garet et al. 2001). In a meta-review of research on PD for technology-enhanced inquiry science, Gerard and colleagues (Gerard et al. 2011) discuss the importance of anchoring experiences in teachers' prior knowledge, and allowing them time to iterate through testing and improvement cycles to adapt the curriculum and instruction to their own contexts. The authors also found that professional guidance was an important factor to help teachers customize the curriculum and that this support takes longer than the initial year of PD and implementation. Other important factors for technology-supported instruction revealed in the study include ready-made curricular materials and partnerships between researchers and teachers to respond to a number of issues, including the technical challenges that impede instruction.

The importance of these insights notwithstanding, the NGSS's requirements for curriculum and instruction will necessitate a large paradigm shift for teachers and a more complex view of teacher learning, as Wilson (2013) and others have noted. PD activities will need to incorporate dynamic and iterative cycles, embedding teachers' experiences in extended opportunities to reflect with colleagues and collectively target problems of practice to improve implementation and student learning outcomes (Wilson 2013). Addressing problems of practice becomes even more vital given the well-documented, steep learning curve teachers experience in adopting new technologies-such as computermodeling supports for complex systems-in their classrooms (Aldunate and Nussbaum 2013; Ertmer et al. 2012). 


\section{Additional considerations for educational improvement}

The task of understanding and addressing real problems of practice also resonates with recent efforts to design and enact models for educational improvement that have a widespread impact. For example, Penuel and colleagues (Penuel et al. 2011) developed a design-based implementation research (DBIR) framework for innovative educational tools and practices to take hold at larger scales. The first element of the DBIR framework is the formation of teams of multiple stakeholders who are focused on persistent problems of practice. Such collaborative teams of researchers and practitioners should address important problems that present challenges to implementation, with practitioners having a say in defining the problems. The second element is a commitment to iterative collaborative design, in which teams focus their efforts on designing, learning from, and redesigning project activities that may address curriculum construction, PD, and organizational change. The third element entails developing theories about how both students and teachers learn in particular contexts, and the activities, resources, and organizations that support this learning. Finally, the fourth element of the DBIR framework concerns developing capacity for sustaining change within systems through intentional efforts to develop organizational infrastructures.

Similarly, the Carnegie Foundation's Core Principles of Improvement (Bryk et al. 2015) promote articulating problems of practice experienced by the central actors, understanding the variation of conditions in which the problems exist and can be addressed, collecting information first-hand, and engaging in cycles of planning, doing, studying, and acting, for which change is measured and tracked over time. Lastly, changes and improvements are accelerated through networked communities. In Carnegie's principles and the DBIR framework, practitioners and their situated experiences factor prominently in design, implementation, and redesign decisions that must be documented and examined to maximize potential for scalable positive change.

We build from this body of research to investigate our two focal research questions about PD supports to teach complex systems, and the subsequent student classroom experiences and learning outcomes when these supports are implemented.

\section{Methods}

\section{Context}

This PD design and development study was conducted between August 2012 and June 2014. We worked with the same teachers over the course of the study, who themselves worked with separate cohorts of students in the 2012-2013 and 2013-2014 academic years. Teachers participated in 2 weeklong summer PD workshops (one workshop per summer, $30 \mathrm{~h}$ each) and follow-up Saturday workshops during the school year (approximately two workshops per semester, $10 \mathrm{~h}$ per year).

PD activities included hands-on training in five biology units on the topics of Genetics, Evolution, Ecology, the Human Body, and Animal Systems. The units entail working with agent-based simulations that combine graphical blocks-based programming with a 3-D game-like interface, as illustrated in Fig. 1a, b. Figure 1a shows the graphical programming language in which computational procedures are built into easily assembled blocks (Begel 1996; Roque 2007) to execute commands. Using the blocks programming language, 
a

The simulation allows students

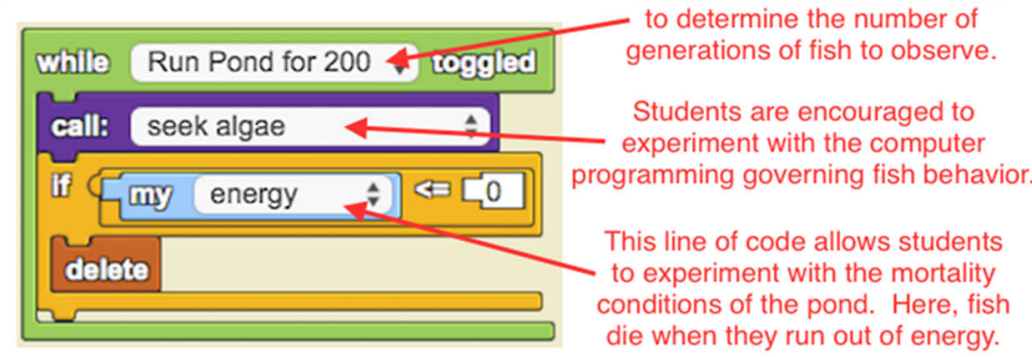

b

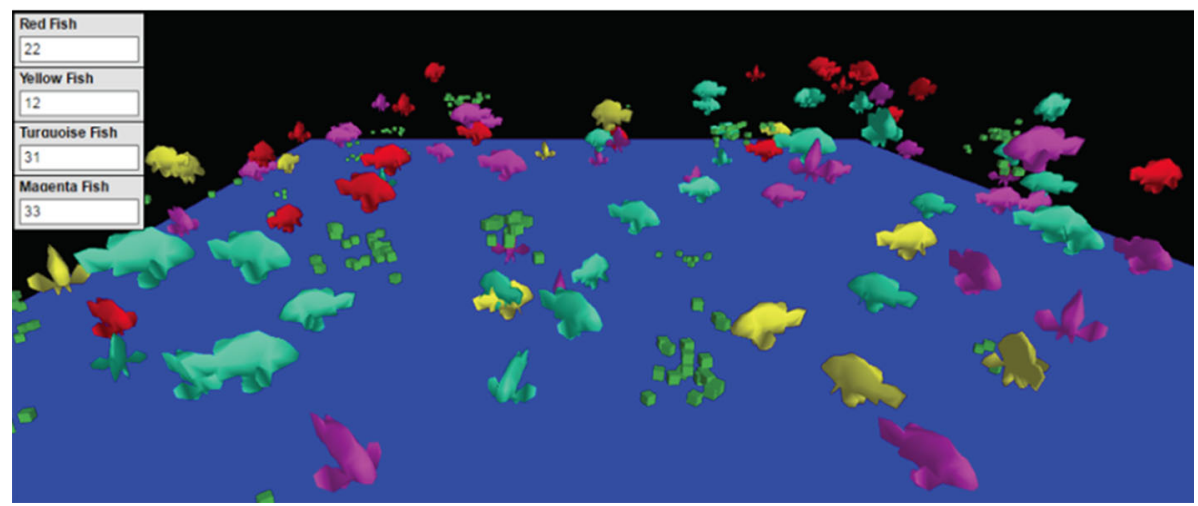

Fig. 1 a The blocks-based programming interface in which students control properties of their virtual systems, b StarLogo Nova translates blocks of computer code into a virtual 3D ecosystem of fish, grasses, and algae

users can simply drag and drop blocks of code, which are organized into categories. The blocks-based language eliminates the need for students to know or remember command names and the accompanying syntax, which are both significant barriers to novice programmers. Figure $1 \mathrm{~b}$ shows how the language is translated into the graphical interface of the system being modeled.

The screenshot in Fig. 1b is from the unit, "Modeling a Pond Ecosystem," in which students are asked to build an ecosystem made up of interacting and interdependent parts. Students learn that biotic (living) and abiotic (non-living) variables are constantly interacting with and changing each other. They learn about the concepts of random motion, competition, reproduction rates, and energy, in an effort to support student understanding of how healthy ecosystems operate.

All the units include working through experiments that provide experiences in core scientific practices as outlined in the NGSS, such as analyzing and interpreting data, engaging in argument from evidence, and obtaining, evaluating and communicating information (see Fig. 2 for a curricular argumentation prompt). Students normally work in groups of 2 or 3 to complete the units. There is no set sequence for the units; instead, teachers can implement them in the order that suits their school curriculum. The curricular materials for each unit take 2-3 days to complete and include popular and academic literature about complex systems as well as short movies, PowerPoint presentations, and teacher and student activity guides. 


\section{Group Discussion \\ Has the fish population evolved? \\ If so, which contributing factor of evolution, genetic drift or natural selection, was most important? Explain your reasoning. \\ Our claim is...}

\section{Our evidence for this is...}

\section{Our reasons are that...}

Fig. 2 Curricular example of scaffolding the scientific argumentation process with the simulation activity

PD activities in the summer included training in complex systems structures and processes - such as feedback, interdependence, self-organization, emergence, and scale. Other activities required teachers to complete all the units in partners to learn about what their students would experience, extended reflection with each other and the research team on how the units could be improved, pedagogical issues they foresaw in terms of implementing the units in class, e.g., how to make connections to the regular biology curriculum, and how to conduct inquiry-based experiments, argumentation, and explaining complex systems concepts to their students. Teachers also spent time planning how the units would fit into the scope and sequence of their courses, and brainstormed ways that the curricula could be modified to meet their student population needs, e.g., learning how to program.

During the school year, teachers implemented the units in their biology classes. Approximately twice a semester, teachers assembled in Saturday morning workshops to share their experiences and to participate in further training based on feedback from implementation efforts. Teachers understood from the beginning of the project that they were co-testers and co-collaborators, and that their feedback about any classroom issues was critical to redesigning resources for optimal learning. We then collected a series of data sources to understand what was working and what was not working in the first year. Teachers moved fully into co-designer roles after the first year of implementation. During the second summer workshop, several teachers led workshop sessions and shared additional curricular supports they created during the year. Teachers also worked in teams to develop assessments, create differentiated opportunities for second-language learners, and locate additional topics in the school biology curricula for which complex systems could be highlighted.

\section{Participants}

We recruited 10 teachers - seven women and three men-from seven Boston-area public schools. The teachers came from a diverse set of schools. One school was as high as $76 \%$ ethnic/racial minorities, while another school was almost entirely White (3\% minority). School-level percentages of low-income students ranged from 14 to $80 \%$. The percentage of students considered proficient or advanced on the state standardized science test ranged from 49 to 94 . Teachers, on average, had 8.5 years of teaching experience, with a range of 3.5-19 years. 
We collected student data in 10 classrooms from a total of 363 students in the first year and 361 students in the second year, with students drawn from all four high school grades and from vocational to AP levels. The schools did not release individual student demographic and achievement data to us, so we cannot report accurate sample data in these areas. However, due to the range of classrooms and academic levels, we believe that the students we worked with are a relatively representative sample of the population-level statistics that are reported. Table 1 provides further demographic details of the student population. The population of students used for each data set varies based on the number of complete sources. We could not control for the academic level or grade teachers taught in the first and second year, therefore, the two cohorts of students look different in that the second cohort was slightly older and more advanced. However, as we have run paired $t$ tests and ANOVAs with the student level data (see below) and have compared the cohorts in terms of growth rather than raw scores, we decided to include all grade levels and tracks in order to increase the sample size.

\section{Data sources and analyses}

To investigate our research questions, we collected seven data sources in each of the 2 years. To understand the PD supports teachers needed, we conducted year-end interviews and collected year-end PD surveys. We also collected classroom observations, videotaped footage of selected professional development discussions, and facilitator perceptions of teachers' classroom implementations in a year-end focus group interview (only in the first year). These latter three data sources are used mainly to support themes that emerged from the first two data sources and were not systematically analyzed for this study. To understand the extent to which students experienced changes in classroom learning activities, we administered a classroom experiences survey to students and conducted two knowledge

Table 1 Descriptive statistics on cohorts

\begin{tabular}{lcc}
\hline Student characteristics & $2012-2013$ Cohort & 2013-2014 Cohort \\
\hline Number of students (n) & 363 & 361 \\
Gender & 160 & 157 \\
Male & 177 & 198 \\
Female & & \\
Track & 64 & 149 \\
Honors & 0 & 21 \\
AP & 172 & 113 \\
Standard & 65 & 23 \\
Vocational & & \\
Grade & 137 & 170 \\
9 th & 71 & 75 \\
10th & 61 & 92 \\
11th & 5 & 14 \\
12th & 46.3 & 49.3 \\
Avg. participants per teacher & &
\end{tabular}


tests in biology and complex systems content. Data sources and analyses are described in further detail below.

\section{Year-end interviews and PD surveys}

We administered a year-end interview with teachers to collect their impressions of participating in the project and ideas for how the project could be improved. The semistructured interview consisted of 20 questions and lasted for approximately $45 \mathrm{~min}$. Teachers were asked to respond to questions about project activities that included teaching through modeling, programming, argumentation, biology content, the teacher and student activity guides, and complex systems. The responses analyzed for this study came from the following prompts, "What were the easiest ones [referring to project activities] to implement?"; "What were the most challenging ones to implement?"; "What did you do to overcome the challenges?"; and "Were there contextual variables that made it more or less difficult to implement the project?"

Interviews were digitally recorded, transcribed, and mined for themes that would indicate important supports needed to successfully implement the project resources. The themes were then assembled into a categorization manual for coding and to obtain interrater reliability. From the year-end interviews for Year 1 and Year 2, a total of 224 responses were coded in five categories of PD supports, which are described in Table 2. We conducted training on the categories with two researchers who are part of the research team but did not analyze this data set. These two raters then independently coded 49 responses, which is equivalent to $22 \%$ of the data. The reliability test on the coding scheme yielded an alpha score of 0.931 . The remaining codes were assigned by two other members of the research team.

Teachers also responded at the end of the year to an online PD survey in which they were asked a series of questions related to their PD experiences throughout the year and how those experiences related to their abilities to implement project resources in their classrooms. Questions asked whether teachers believed the summer and Saturday workshops were helpful in terms of implementation. They were also asked to identify the most and least helpful PD activities, as well as anything that should be changed if the PD were to be offered again. Responses were analyzed using the same categorization manual constructed for year-end interviews. In total, 99 responses were coded from the PD surveys by one member of the research team. In the results, we report on frequency of codes in each category of the year-end interviews and PD surveys combined.

\section{Classroom observations, facilitator year-end focus group interviews, videotaped footage of professional development discussions}

Teachers were observed implementing project activities in their classrooms by a project facilitator, on average, twice each year. The observation protocol included information about teaching with the simulations, the comfort with the pedagogical approach (e.g., argumentation), and teaching the complex systems and biology content. At the end of each observation, facilitators conducted a brief interview soliciting information about how teachers felt the implementation went.

In the summer between the first and second year, all project facilitators participated in a 90-minute interview, in which we asked them to recall anecdotal information and impressions of each teacher they observed and facilitated in the classroom. Project facilitators consulted fieldnotes and referred to email correspondence and informal 
Table 2 Categories of PD supports

\begin{tabular}{|c|c|c|}
\hline $\begin{array}{l}\text { Categories of PD } \\
\text { supports }\end{array}$ & Definition & Example \\
\hline Time and experience & $\begin{array}{l}\text { Teachers need more time and } \\
\text { experience to deliver the project } \\
\text { activities and to feel comfortable with } \\
\text { the resources especially because } \\
\text { complex systems, argumentation, and } \\
\text { computational modeling are new to } \\
\text { many teachers and learned all at once }\end{array}$ & $\begin{array}{l}\text { But I think if I had maybe a little bit } \\
\text { more time to learn it, I think that was } \\
\text { one of the things that I suggested if I } \\
\text { had more time and I was more versed } \\
\text { with it, so that I think I would have } \\
\text { been able to help them more }\end{array}$ \\
\hline $\begin{array}{l}\text { Hands-on practice } \\
\text { and training }\end{array}$ & $\begin{array}{l}\text { Teachers need to actively participate in } \\
\text { doing the activities such as playing } \\
\text { with the models and learning to } \\
\text { program. Continual hands-on training } \\
\text { with facilitation is vital to computer- } \\
\text { supported complex systems curricula }\end{array}$ & $\begin{array}{l}\text { I am learning computational } \\
\text { [programming] by stumbling through } \\
\text { this. That's why it's probably, I find, a } \\
\text { weaker thing we can teach here. I } \\
\text { would need more training in that to } \\
\text { learn [how to teach it] }\end{array}$ \\
\hline Just-in-time supports & $\begin{array}{l}\text { Teachers need to be supported } \\
\text { developmentally as they learn to } \\
\text { master different pedagogical } \\
\text { approaches, knowledge, and skills that } \\
\text { have steep learning curves, e.g., } \\
\text { computer programming. This requires } \\
\text { PD developers to formatively assess } \\
\text { where teachers are in their } \\
\text { development and provide extra } \\
\text { supports in a timely way }\end{array}$ & $\begin{array}{l}\text { I would really like to see more about the } \\
\text { complex systems ideas in a lot of } \\
\text { different examples. I'm sort of read } \\
\text { up. Now that I know there were some } \\
\text { authors and can look [the definitions] } \\
\text { up and figure out a few things, [I'm } \\
\text { ready for more] }\end{array}$ \\
\hline $\begin{array}{l}\text { Interaction and } \\
\text { building knowledge } \\
\text { within the } \\
\text { community }\end{array}$ & $\begin{array}{l}\text { Teachers need to share ideas and } \\
\text { strategies with each other to explore } \\
\text { implementation issues and solutions. } \\
\text { Teachers also need to work as } \\
\text { research partners with PD developers } \\
\text { to ensure that modifications to project } \\
\text { activities respond to teachers' situated } \\
\text { needs }\end{array}$ & $\begin{array}{l}\text { I would say by practice and } \\
\text { communicating with the group. That } \\
\text { was probably the best set of examples } \\
\text { for me. It just helped communicating } \\
\text { with the other teachers and } \\
\text { communicating with all of you doing } \\
\text { the presentations on the complex } \\
\text { systems and giving us ideas }\end{array}$ \\
\hline $\begin{array}{l}\text { Supporting teacher } \\
\text { beliefs }\end{array}$ & $\begin{array}{l}\text { PD developers need to work with } \\
\text { teacher beliefs about these newer } \\
\text { approaches to science teaching. } \\
\text { Teachers need support to understand } \\
\text { essential features of scientific learning } \\
\text { and practice such as building } \\
\text { computer models. Teachers need to } \\
\text { understand that students are capable } \\
\text { of participating in such learning } \\
\text { events }\end{array}$ & $\begin{array}{l}\text { [Regarding computer programming] I } \\
\text { think [students] need to see some } \\
\text { relevance really fast because it gets } \\
\text { boring and old quickly. I'm putting all } \\
\text { these squares together. But what am I } \\
\text { doing this for? What's the point of } \\
\text { this? Where is it leading to? }\end{array}$ \\
\hline
\end{tabular}

conversations they had with teachers about the classroom implementation. The focus group interview was conducted to ascertain what project activities and goals needed to be further supported in the second summer workshop.

Several PD activities were videotaped to capture teachers' ideas and responses to the activities in order to understand how to support them in the classroom. We include excerpts from one PD discussion in the analysis that occurred at the beginning of the second semester of the first year around the subject of helping students learn how to program models. 
As noted above, these three data sources were not systematically analyzed but instead were used to corroborate themes that emerged from the first two data sources.

\section{Student classroom experiences surveys}

At the start and end of the school year, students completed a 35-item survey scored on a 5-point Likert-scale (i.e., strongly disagree [1] to strongly agree [5]) that collected students' experiences in five factors related to the project goals. Items were included with a factor loading of 0.4 and above. The first factor measured students' understanding of scientific practices $(\alpha=0.905)$ and included items such as "Being able to solve real world problems," and "Being able to critically evaluate scientific claims." The second factor measured students' perceptions of the scientific practices they performed in science class $(\alpha=0.810)$ and included items such as, "I often design and construct my own experiment or investigation (on the computer or off the computer) in class," and "There are times I think about or solve a biology question in more than one way to help my understanding." The third factor measured students' classroom experiences using computer technologies to learn science $(\alpha=0.860)$ and included items such as, "I use computer models to visualize scientific ideas," and "I use computer simulations, images or animations to collect and analyze data and to draw conclusions." The fourth factor measured students' interest in science $(\alpha=0.909)$ and included items such as, "I think science is interesting," and "I am motivated to learn more science in the future." The fifth factor measured students' perception of how they learn in the science class $(\alpha=0.793)$ and included items such as, "I often work together with other students to learn about science," and "I often have opportunities to find out answers on my own."

Growth in each factor and aggregate scores are reported through a repeated measures ANOVA for students in Year 1 and students in Year 2 of the study.

\section{Student knowledge tests}

Biology content understanding was assessed using 14 multiple-choice questions compiled from several state and national standardized science exams. ${ }^{1}$ Students completed the test both at the start and end of the school year so that learning gains could be assessed. A paired $t$ test was conducted to analyze growth in student biology understanding.

Students also completed an assessment of complex systems understanding, both at the start and end of the school year. This instrument consisted of an open-ended ecology prompt, described below, asking students to write down anticipated changes in a biological system:

Imagine a flock of geese arriving in a park in your town or city, where geese haven't lived before. Describe how the addition of these geese to the park affects the ecosystem over time. Consider both the living and non-living parts of the ecosystem.

Responses were scored on a scale of 1 (not complex) to 3 (completely complex) for each of four different dimensions of complex systems understanding, which are listed in Table 3. These components were derived from earlier research (Yoon 2008, 2011;

\footnotetext{
1 We consulted the 1999, 2000, 2001, 2010, and 2011 New York State Board of Regents Biology exams; the 2009 California Standards Test in Biology; and the 2000 and 2009 National Assessment of Educational Progress (NAEP) exams.
} 
Table 3 Categories of complex systems components

\begin{tabular}{|c|c|}
\hline $\begin{array}{l}\text { Complex systems } \\
\text { components }\end{array}$ & Descriptions \\
\hline Predictability & $\begin{array}{l}\text { The emphasis is on the predictability of the effects caused by the agent in } \\
\text { question. According to the clockwork framework, the way in which a part or } \\
\text { agent operates or affects other components of the system is predictable. In a } \\
\text { complex framework, it is impossible to anticipate precisely the behavior of the } \\
\text { system. This is because the actions of agents cannot be predicted (as random } \\
\text { forces or chance factors can affect an agent's actions) even if we know the rules } \\
\text { or characteristics of the agent }\end{array}$ \\
\hline Processes & $\begin{array}{l}\text { Processes refer to the dynamism of the mechanisms that underlie the phenomena } \\
\text { (i.e., how the system works or is thought to work. In a clockwork framework, } \\
\text { there is a beginning, middle, and end in the system. The system is composed of } \\
\text { static events. While perturbations (actions by/on parts) in the system may cause } \\
\text { change to occur, the change terminates once an outcome is achieved. In a } \\
\text { complex systems framework, there is no definite beginning and end to the } \\
\text { activity. System processes are ongoing and dynamic }\end{array}$ \\
\hline Order & $\begin{array}{l}\text { The focus is the organization of the system or phenomenon as centralized or } \\
\text { decentralized. A clockwork framework assumes that all systems are controlled } \\
\text { by a central agent (e.g., all action is dictated by a leader). Order is established } \\
\text { top-down or determined with a specific purpose in mind. In a complex systems } \\
\text { framework, control is decentralized and distributed to multiple parts or agents. } \\
\text { Order in the system is self-organized or 'bottom-up' and emerges spontaneously }\end{array}$ \\
\hline Emergence and scale & $\begin{array}{l}\text { Emergence refers to the phenomenon where the complex entity manifests } \\
\text { properties that exceed the summed traits and capacities of individual } \\
\text { components. In other words, these complex patterns simply emerge from the } \\
\text { simpler, interdependent interactions among the components. In a clockwork } \\
\text { framework, parts of the system are perceived to be isolated with little } \\
\text { interdependency among them. This is because of the linear nature that } \\
\text { characterizes these relationships. Thus, there are no large, global patterns that } \\
\text { emerge from actions imposed on the system. Rather, these actions cause only } \\
\text { localized changes (e.g., geese eat plants causes a decrease in grass). In a } \\
\text { complex system, because parts or agents are interdependent in multiple ways, an } \\
\text { action (small or large) that is imposed on the system may have large and far- } \\
\text { reaching consequences on the numerous parts and agents of the system. This } \\
\text { may in turn result in large-scale change and evolution }\end{array}$ \\
\hline
\end{tabular}

Jacobson et al. 2011; Pavard and Dugdale 2000). Aggregate scores on this assessment ranged from 4 to 12 .

Due to the complexity of this coding task, three raters were rigorously trained over a series of several weeks. All raters were then asked to code $20 \%$ of the data. We then ran reliability tests between pairs of raters in order to determine which raters had the highest alpha scores in each of the complex systems categories. Alpha scores for each pair ranged between 0.731 and 0.823 . The pairs of raters then scored all of the student responses in their assigned categories. All discrepant codes were discussed and a single code was assigned. Student growth in complex systems understanding was determined from their scored responses through a paired $t$ test. 


\section{Results}

\section{PD supports needed by teachers}

In their year-end interviews and PD surveys, teachers articulated five categories of PD supports needed to be able to implement the project activities that involved instruction in modeling, programming, complex systems, scientific practices such as argumentation, and integration in biology content. Figure 3 shows the overall frequencies in each category for Year 1 and Year 2. From the figure, we can see that teachers discussed a greater number of PD supports in Year 2. At the end of their second year, teachers had a much stronger sense of their own capacity for instruction in the project. They also felt more confident about their understanding of what did and did not work in the classroom over the 2 years and could identify factors that contributed to their overall instructional improvement in the second year.

Within the five categories, teachers discussed whether they felt particular activities were challenging in terms of implementation or whether they thought their instruction and practices had been supported by the project and by the PD. As this was a design and development effort, the project team continually monitored and sought teachers' ideas about how the project could be improved. In Year 1 about $30 \%$ of the responses indicated challenges teachers experienced in their classroom implementation that could be directly supported by PD activities. Based on feedback in Year 1, we modified resources and PD to respond to teacher needs. In Year 2, the number of challenges reported dropped about $10 \%$. Results and examples for each category are detailed below.

\section{Time and experience}

Teachers indicated that they needed more time and experience in order to feel more comfortable and better able to instruct using project resources. Due to the variety of new types of resources, knowledge, and skills to be implemented and for which teachers had little prior experience, teachers in the first year said that 1 year was not enough in terms of PD participation. However, more responses fell into the supported category at the end of Year 2, with more teachers indicating that they felt that their two-year participation helped them to become more capable and confident in their understanding and classroom implementation abilities. The following excerpts from a second-year interview with one teacher, Kathryn (K), illustrates this point:

I: You mentioned before that you felt that your implementation had improved. What do you think led to that improvement?

K: Definitely like the fact that we spent 2 years learning about the simulations and how to use them in our classroom.

.....

K: I definitely feel like it was overall more successful just because I felt more comfortable with the simulations myself. I felt more comfortable with the packets. I felt more comfortable with the material, with the ideas of what a complex system is, and I kind of learned from last year what worked well and what didn't. You know, I probably checked in with students more frequently or gave them stopping points to stop and just call me over to look at their work and to check it and make sure everything was going okay. I did that a lot more this year. 


\section{Frequency of PD Supports Articulated By Teachers}

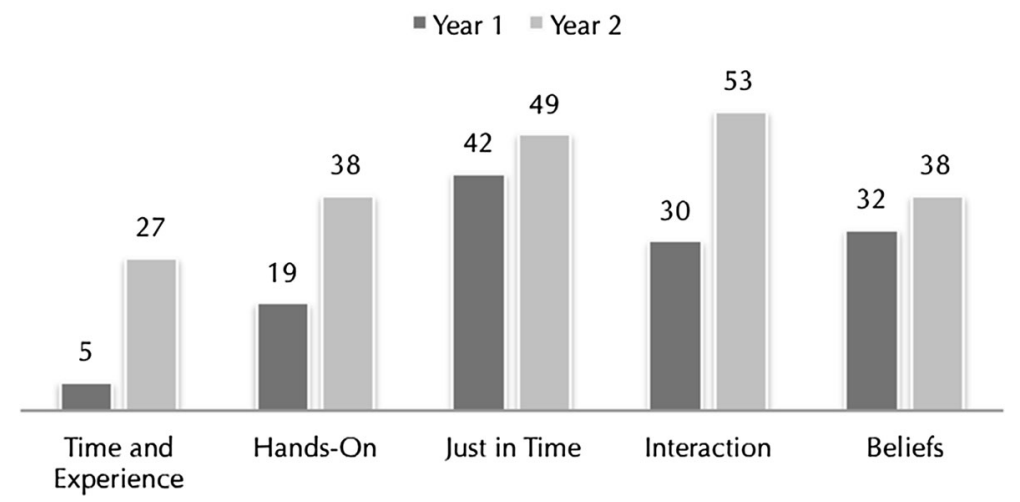

Fig. 3 Frequency of PD supports articulated by teachers

Based on classroom observations, PD discussions, and informal comments from facilitators, there was a marked difference for Kathryn and all the teachers in their second year in terms of their ability to manage the complex array of project resources. Facilitators commented that few teachers in their first year focused on the core complex systems ideas embedded in the simulations (a point discussed in more detail below). Instead, teachers' efforts in the first year were largely spent making sure that the models were running and managing the classroom dynamics that emerged from the novel computer-supported pedagogy.

\section{Hands-on practice and training}

Teachers suggested that the hands-on practice and training they received in the PD was important to their success in the classroom. Due to the novelty of computer programming as well as new scientific practices and content, teachers needed practice working alone and with facilitators to feel comfortable with the project resources. Teachers responded favorably in both years with respect to how well they felt supported in hands-on training and practice, which is not surprising considering that the PD placed a great deal of emphasis on helping teachers become comfortable using the models in instruction. However, there were a few activities and resources teachers needed more practice with and support in using. For example, after the first year of implementation, some teachers said that the argumentation activities embedded in the units were challenging to teach and assess. The project team designed a PD session in the second summer workshop to support teachers to improve their understanding and teaching of argumentation. In the following excerpt, Mary (M) talks about how working through sample argumentation exercises using student responses from Year 1 helped her to become much more adept at assessing student argumentation practices:

M: Yeah. So, I think by doing it over and over- I remember in one of the PDs we did them and then read all of ours aloud. The actual 'doing it' in the PD was really, really helpful.

I: The actual writing of it, or do you mean when we read the students' answers and then graded them; or was it you sitting down and doing the actual assignments? 
M: I think both. I think they were equally helpful. I think seeing how students responded and then being able to say, "Oh, I understand why they thought that." But then also doing them myself because it makes you think, "Alright, well here's what the answer should be and here's why they could have thought that." So, I think they're both important.

During both summer and school-year PD workshops, all teachers relished their time on the computers working closely with project facilitators to improve their modeling skills and understanding. Conversations often ensued about how teachers would need to make adaptations to the organization of their classrooms as well as how they would integrate the units into their existing curricula. It was clear that the focus on hands-on practice and training was a valuable feature of the PD for teachers' own learning and also to help them envision implementation strategies.

\section{Just-in-time supports}

The greatest number of teacher responses fell into the category of just-in-time supports, likely due to the number of new skills and the amount of knowledge required of teachers to participate successfully in the project. During the summer workshop, teachers were trained on the different aspects of unit implementation all at once, but mastery of different skills and knowledge came at different times, which required the project team to formatively assess teachers' developing pedagogical expertise. One insight came in the first year-end interview with Emily, who knew more biology content than most other members in the group. When asked if there was anything the project should do differently in the second summer workshop, she said she had become increasingly more comfortable with using the models in her instruction but found it challenging to highlight the embedded complex systems concepts:

I think we should take time to consider how to teach complex systems through the models. Each model is an example of a complex system, but I didn't find guidance in the teacher guides or our discussions as to how to teach it to students. I found that most of the PD related to complex systems was to teach us how to think about them, not how to teach them. Maybe that is the next step?

Referring to specific unit activities, Anna similarly found teaching about complex systems difficult at the beginning:

It was just kind of hard to figure out where to begin when all this started. How do I introduce complex systems and the turn and walk or whatever it was called, the flocking of the birds and then the Hexbugs. When I had all this stuff in my head, the Hexbugs; having them go though that activity and just kind of putting [it] altogether and kind of making it make sense with the models, it was just hard to figure out where to begin.

In the second summer workshop, we worked with teachers to support their complex systems pedagogical content knowledge by creating vocabulary lists for students, highlighting the connections between the biology content and systems concepts, and providing extra resources such as short movie clips and popular culture examples that helped teachers support their students in understanding complex systems content within biology. This next excerpt shows how Mary responded favorably to this effort: 
Creating additional lesson resources/linking how they could be incorporated into our curriculum was great. There was a spreadsheet that tied together the complex system activities such as turn and walk, gamblers dilemma, angels and demons to the units, which was great!

The classroom observations over the 2 years generally supported this finding, in that teachers demonstrated developmental stages in building their expertise with project activities. Interestingly, for most teachers the explicit integration of complex systems content in their instruction came much later in their training and with a great deal more support than the project team initially anticipated.

\section{Interaction and building knowledge within the community}

Another category that was well represented in teachers' responses was interaction with peers and with the project team as research partners. Within this category the responses were mixed in terms of whether teachers felt interaction was a challenge or supported. In response to the survey question about the most important features of the PD activities, Anna wrote:

It was great to learn from everyone and share ideas and collaborate on resources, materials, and ways people teach. I still use some of the tools that others suggested and shared information on. Thank you! It was the best PD I ever had. And some of the best people I got the chance to meet.

Amanda similarly discussed the importance of learning from others in her Year 2 interview:

Just hearing their situations, whether it's their successes or their struggles, even their examples, things that they have thought of while they've been implementing. It just helps to hear that you're not necessarily the only one struggling or you are just as excited as the other teachers to find ways to incorporate [complex systems] even more than just with simulations and stuff.

However, some teachers wanted more collaboration and problem solving with other teachers. For example, Robert wrote:

I would have preferred to just get together with other teachers to discuss what we do in our classrooms. Or, even better, it would have been really nice to work with another teacher in a different setting to carry out an observation of implementation, just to see how others do it and what their challenges are.

Despite the differences of opinion expressed in these excerpts, teachers' unanimously signaled, in all teacher data sources collected, the importance of being able to connect with each other. During PD workshop discussions, teachers talked about how much there was to master in this new approach to learning and that being able to share insights with other teachers really supported their ongoing efforts.

\section{Supporting teacher beliefs}

The final category of PD supports revealed in teachers' responses was the need to address teacher beliefs about what counts as science teaching and learning. One of the central challenges we experienced with teachers was helping them to see that building 
computational models was a core scientific practice. Teachers were also not convinced that some of their students could handle programming. These beliefs are captured precisely in the following excerpt of workshop footage in which teachers discussed their impressions after learning how to program an ecological model for the first time. Here Robert summarizes the sentiment of the group:

I think I had some similar thoughts as Anna as to the relevance for a bio class and time. And I have to qualify this statement with what kinds of students I teach. This kind of activity may work with a motivated student where you can give them the activity and send them off. I know that my current reality and my current students would not understand why they were doing this at all. They do understand the modeling. But this is way beyond what they would be able to do and see the relevance with. Like where is the Biology?

In the next PD session, we launched into discussions about how scientific research requires modeling for prediction and that it is a core aspect of the nature of science. We had teachers read "Why Model" by Joshua Epstein, one the pioneers of agent-based modeling, in which he lists 16 reasons why scientists model (Epstein 2008). In our regular units, we asked students to "go under the hood" and change parameters of the program to alter the simulations. Robert's students, in particular, found the programming aspect interesting, and at least two sets of students decided to build simulations for their science fair projects on their own time. By the end of the 2 years together, we saw shifts in teachers' beliefs about why building models belongs in science courses. Here is an excerpt from Robert's Year 2 interview on the topic:

I: Okay and so many teachers did not feel that computational modeling should be part of their Biology curriculum? Do you agree?

R: No.

I: Yeah. So why is that?

$\mathrm{R}$ : Well, if complex systems is gonna be part of the curriculum, then you have to teach computational modeling with it because there's no other way for students to understand the complex systems unless they model it.

I: Ah ha!

R: I'm not a definition giver so if I give definitions and I don't give them real life examples, then I might as well just throw it away. So to me, complex systems thinking, the usefulness and utility of it, is to do the computational modeling with it; otherwise I'm not actually teaching anything.

\section{Changes in students' experiences in the classroom}

In this study we were also interested in understanding how PD activities influenced students' classroom learning experiences and whether there was a difference between Years 1 and 2 based on improvements made over the 2 years. We measured students' classroom experiences on five factors related to project goals.

Factor 1: Understanding of scientific practices

Factor 2: Perceptions of the scientific practices performed in science class

Factor 3: Classroom experiences using computer technologies to learn science

Factor 4: Interests in science

Factor 5: Perception of how students learn in science class 
Tables 4 and 5 show the results of the repeated measures ANOVA tests completed for Years 1 and 2. In Year 1 there was significant growth in three of the five factors, with the largest growth in students' classroom experiences using computer technologies. There was no significant growth in students' understanding of scientific practices or their interests in science. In Year 2 there was significant growth in all five factors and an increase in effect sizes from Year 1 to Year 2. In the aggregate, the effect size moves from a small to a medium effect (Cohen 1988). These results lend some validity to the five PD supports articulated in the previous section. We do acknowledge that the demographics of the two student cohorts were slightly different. For example, Year 2 includes AP students. However, we believe that the results are still promising for our study design.

\section{Changes in student knowledge tests}

Similar to student classroom experiences, we were interested in understanding differences in student learning outcomes in the 2 years. From students' pre- and post-surveys, the results indicated gains in both content areas for both years. Table 6 displays results from the paired $t$ test of biology scores, conducted for Years 1 and 2. The results show that student scores increased significantly from pre- to post-tests in both years; however, we see a larger effect size in Year 2.

The analysis of responses from the complex systems ecology prompt show similar gains. Table 7 shows that students' complex systems understanding demonstrated positive significant growth, in both years. However, we see a much larger effect size in Year 2.

Our research design does not allow us to identify whether or not these gains would have occurred in the absence of our project resources in each year. But growth clearly did happen within each year, and more growth happened in the second year. The effect sizes of 0.67 and 0.65 are interpreted as medium effects in Cohen's d terms (Cohen 1988). Moreover, according to Bloom and colleagues, ninth graders typically experience an effect size of around only 0.19 in science learning over the course of their freshman year as measured by several nationally normed tests (Bloom et al. 2008). As ninth grade was the

Table 4 Growth in students' classroom experiences, year 1

\begin{tabular}{|c|c|c|c|c|c|c|}
\hline Factors & Test & Mean & SD & $F$ stat & & Cohen's d \\
\hline Factor 1 & Pre & 4.021 & 0.637 & \multirow[t]{2}{*}{0.39} & & \multirow[t]{2}{*}{0.04} \\
\hline Science practices & Post & 4.043 & 0.632 & & & \\
\hline Factor 2 & Pre & 3.246 & 0.566 & \multirow[t]{2}{*}{16.79} & $* *$ & \multirow[t]{2}{*}{0.24} \\
\hline Practices in class & Post & 3.393 & 0.658 & & & \\
\hline Factor 3 & Pre & 3.012 & 0.776 & \multirow[t]{2}{*}{143.43} & $* *$ & \multirow[t]{2}{*}{0.84} \\
\hline Computers in class & Post & 3.647 & 0.728 & & & \\
\hline Factor 4 & Pre & 3.492 & 0.827 & \multirow[t]{2}{*}{2.16} & & \multirow[t]{2}{*}{0.07} \\
\hline Interest in science & Post & 3.434 & 0.854 & & & \\
\hline Factor 5 & Pre & 3.428 & 0.585 & \multirow[t]{2}{*}{22.52} & $* *$ & \multirow[t]{2}{*}{0.29} \\
\hline How students learn & Post & 3.613 & 0.681 & & & \\
\hline \multirow[t]{2}{*}{ Aggregate } & Pre & 3.440 & 0.480 & \multirow[t]{2}{*}{46.24} & ** & \multirow[t]{2}{*}{0.36} \\
\hline & Post & 3.626 & 0.558 & & & \\
\hline
\end{tabular}

$* * \mathrm{p}<0.01, \mathrm{n}=321$ 
Teaching about complex systems is no simple matter...

Table 5 Growth in students' classroom experiences, year 2

\begin{tabular}{|c|c|c|c|c|c|c|}
\hline Factors & Test & Mean & SD & $F$ stat & & Cohen's d \\
\hline Factor 1 & Pre & 4.099 & 0.539 & 28.01 & $* *$ & 0.33 \\
\hline Science practices & Post & 4.270 & 0.487 & & & \\
\hline Factor 2 & Pre & 3.237 & 0.537 & 28.68 & $* *$ & 0.34 \\
\hline Practices in class & Post & 3.422 & 0.567 & & & \\
\hline Factor 3 & Pre & 3.158 & 0.707 & 236.93 & $* *$ & 1.12 \\
\hline Computers in class & Post & 3.897 & 0.607 & & & \\
\hline Factor 4 & Pre & 3.591 & 0.722 & 13.70 & $* *$ & 0.17 \\
\hline Interest in science & Post & 3.718 & 0.767 & & & \\
\hline Factor 5 & Pre & 3.445 & 0.607 & 45.14 & $* *$ & 0.44 \\
\hline How students learn & Post & 3.714 & 0.623 & & & \\
\hline \multirow[t]{2}{*}{ Aggregate } & Pre & 3.506 & 0.442 & 149.10 & $* *$ & 0.67 \\
\hline & Post & 3.804 & 0.448 & & & \\
\hline
\end{tabular}

$* * \mathrm{p}<0.01, \mathrm{n}=310$

Table 6 Results for paired $t$ test biology content learning

$* * \mathrm{p}<0.01$

Table 7 Results for paired $t$ test complex systems content

$* * \mathrm{p}<0.01$

\begin{tabular}{lllllll}
\hline Year & Test & Mean & SD & $t$ & & Cohen's d \\
\hline Year 1 & Pre & 6.71 & 2.31 & 10.73 & $* *$ & 0.56 \\
$\mathrm{n}=363$ & Post & 8.13 & 2.78 & & & \\
Year 2 & Pre & 7.67 & 2.36 & 12.50 & $* *$ & 0.67 \\
$\mathrm{n}=346$ & Post & 9.43 & 2.47 & & & \\
\hline
\end{tabular}

\begin{tabular}{lllllll}
\hline Year & Test & Mean & SD & $t$ & & Cohen's d \\
\hline Year 1 & Pre & 6.18 & 1.48 & 3.51 & $* *$ & 0.19 \\
$\mathrm{n}=354$ & Post & 6.51 & 1.49 & & & \\
Year 2 & Pre & 5.80 & 1.23 & 12.26 & $* *$ & 0.65 \\
$\mathrm{n}=361$ & Post & 6.79 & 1.29 & & & \\
\hline
\end{tabular}

most common grade level in our study, it is possible that the science learning in our project exceeded that of traditional science classrooms.

\section{Discussion}

Wilson (2013) suggests that helping teachers become knowledgeable and skilled in the requirements of the NGSS is a daunting task-one that will require high quality PD that is embedded in real problems of practice in different contexts, and based on an understanding of teacher learning and training as a complex endeavor. In this study, we sought to identify what supports teachers need to be successful in instruction about complex systems. Overall, we found that to teach effectively about complex systems in the science classroom 
requires an equally complex array of skills and understanding in which effective PD requires a capacity to respond to emergent outcomes.

Of the five PD supports we identified, three-time needed to become comfortable with the project resources, hands-on practice and training, and interactions within a teacher community-were somewhat predictable. Other education researchers have noted that similar PD supports are essential in teacher development (Desimone 2009; Gerard et al. 2011; Lieberman 2000).

What we find most instructive from our results-and in line with the notion of emergent complex patterns associated with complex systems - is the critical role of PD that provided just-in-time supports and that persuaded teachers of the necessity of building models in the science classroom. Working with teachers who were content experts, while at the same time recognizing that a few studies had shown weak teacher understanding of complex systems ideas (e.g., Booth-Sweeney and Sterman 2007; Brown and Schwartz 2009; HmeloSilver and Pfeffer 2004), we felt relatively confident that teachers would be able to see the relationship between complexity and biology content with explicit instruction. What we hadn't anticipated was the extra support needed to help teachers translate this relationship into practice. Even though we included callouts in the teacher guides, many different examples of complex systems that teachers could use with their students, and guided questions to build students' knowledge in their activity packs while working through the simulations, we discovered that this wasn't enough support. As Anna stated, it was difficult for the participating teachers to know where to begin when they also had to help students make sense of the models. Herein lies an essential challenge with respect to computersupported complex systems teaching and learning: This kind of instruction requires helping teachers acquire a more sophisticated, or complex, form of pedagogical content knowledge that simultaneously addresses computer modeling, building models, embedding other scientific practices, and learning about complex systems and their relationship to science content. And we were able to ascertain this insight only through formative assessment of teachers' experiences over an extended period of time working with teachers as authentic research partners. Such just-in-time PD supports over more than the typical summer or one-year training teachers participate in, have been highlighted elsewhere as essential features of high quality PD (e.g., Gerard et al. 2011; Varma et al. 2008). We argue that information sharing structures need to be put into place over the extended life of the PD to provide frequent feedback on important aspects of curricular interventions and teacher's instructional needs that can impact the success of learning experiences in the classroom.

With respect to the findings on supporting teachers' beliefs, we do know that teacher beliefs can significantly influence who has access to high quality instruction (e.g., Prime and Miranda 2006), as well as how science is taught and what science is taught in the classroom (e.g., Jones and Carter 2007). Despite our teachers being self-selected and eager participants, teacher beliefs about computer programming and modeling needed to be addressed in a more systematic way. On the whole, the cohort of teachers was a progressive group continually seeking out new methods to improve instruction. However, their belief in merits of building computational models in the science class turned out to be beyond the threshold of advanced pedagogical methods that they would accept initially, and we had to work hard to change this belief. Our teachers eventually understood the importance of building models, as suggested in Robert's Year 2 interview and echoed in a quote by Wilensky and Reisman (2006), "If you can't build it, you don't understand it" (p. 202). But helping the current and next generations of teachers see model building as a core scientific practice, and then assisting them in effectively incorporating this practice into 
their instruction, is an important challenge that educational researchers must acknowledge and address.

We have demonstrated some evidence that working with these five PD supports improved the classroom learning experiences of students and their content knowledge although there was variation in student grade and ability levels between the two cohorts of students. Moving forward, we intend to take a more controlled experimental approach to ascertain the robustness of the effects and to focus on understanding how different grade and ability levels of students can influence how and what is learned. Ultimately, as teachers were the central focus of this research, we believe that these findings are an important next step in helping teachers to teach about complex systems, which is an area in great need of more research in the field of complex systems in science education. Teaching students about complex systems is no simple matter. And as this article demonstrates, neither is supporting teachers in those efforts, particularly when computer-supported models are involved. But if we take Epstein's quote from the beginning of this article to heart, the "habits of mind" that come from grappling with these complex scientific systems and their models are well worth the toil and struggle.

Acknowledgments This work was funded by the U.S. National Science Foundation Discovery Research K12 (DRL 1019228).

\section{References}

Aldunate, R., \& Nussbaum, M. (2013). Teacher adoption of technology. Computers in Human Behavior, 29, 519-524.

Begel, A. (1996). LogoBlocks: A graphical programming language for interacting with the world (Unpublished advanced undergraduate thesis). Cambridge, MA: Massachusetts Institute of Technology.

Bloom, H. S., Hill, C. J., Black, A. R., \& Lipsey, M. W. (2008). Performance trajectories and performance gaps as achievement effect-size benchmarks for educational interventions. Journal of Research on Educational Effectiveness, 2, 289-328.

Booth-Sweeney, L. B., \& Sterman, J. D. (2007). Thinking about systems: Student and teacher conceptions of natural and social systems. System Dynamics Review, 23(2-3), 285-311.

Brown, M. H., \& Schwartz, R. S. (2009). Connecting photosynthesis and cellular respiration: Preservice teachers' conceptions. Journal of Research in Science Teaching, 46(7), 791-812.

Bryk, A. S., Gomez, L. M., Grunow, A., \& LeMahieu, P. (2015). Learning to improve: How America's schools can get better at getting better. Cambridge, MA: Harvard University Press.

Cohen, J. (1988). Statistical power analysis for the behavioral sciences (2nd ed.). Mahwah, NJ: Lawrence Erlbaum.

Colella, V., Klopfer, E., \& Resnick, M. (2001). Adventures in modeling. New York: Teachers College Press.

Danish, J. (2014). Applying an activity theory lens to designing instruction for learning about structure, behavior, and function of a honeybee system. Journal of the Learning Sciences, 23(2), 100-148.

Desimone, L. (2009). Improving impact studies of teachers' professional development: Toward better conceptualizations and measures. Educational Researcher, 38(3), 181-199.

Epstein, J. (2008). 'Why Model?'. Journal of Artificial Societies and Social Simulation, 11(47). Retrieved from http://jasss.soc.surrey.ac.uk/11/4/12.html.

Ertmer, P. A., Ottenbreit-Leftwich, A. T., Sendurur, E., \& Sendurur, P. (2012). Teacher beliefs and technology integration practices: A critical relationship. Computers \& Education, 59, 423-435.

Garet, M. S., Porter, A. C., Desimone, L., Birman, B. F., \& Yoon, K. S. (2001). What makes professional development effective? Results from a national sample of teachers. American Educational Research Journal, 38(4), 915-945.

Gerard, L. F., Varma, K., Corliss, S. B., \& Linn, M. (2011). Professional development for technologyenhanced inquiry science. Review of Educational Research, 81(3), 408-448.

Gobert, J. (2005). Leveraging technology and cognitive theory on visualization to promote students'science learning. In J. Gilbert (Ed.), Visualization in science education (pp. 73-90). Dordrecht: SpringerVerlag. 
Hmelo-Silver, C. E., Marathe, S., \& Liu, L. (2007). Fish swim, rocks sit, and lungs breathe: Expert-Novice understanding of complex systems. Journal of the Learning Sciences, 16(3), 307-331.

Hmelo-Silver, C. E., \& Pfeffer, M. G. (2004). Comparing expert and novice understanding of a complex system from the perspective of structures, behaviors, and functions. Cognitive Science, 28, 127-138.

Honey, M., \& Hilton, M. (2011). Learning science through simulations and games. Washington, DC: National Academies Press.

Jacobson, M. (2001). Problem solving, cognition, and complex systems: Differences between experts and novices. Complexity, 6(3), 41-49.

Jacobson, M., Kapur, M., So, H., \& Lee, J. (2011). The ontologies of complexity and learning about complex systems. Instructional Science, 39, 763-783.

Jones, G., \& Carter, G. (2007). Science teacher attitudes and beliefs. In S. K. Abell \& N. G. Lederman (Eds.), Handbook of research on science education (pp. 1067-1104). Mahwah, NJ: Lawrence Erlbaum Associates.

Klopfer, E., Yoon, S., \& Perry, J. (2005). Using Palm technology in participatory simulations of complex systems: A new take on ubiquitous and accessible mobile computing. Journal of Science Education and Technology, 14(3), 285-298.

Levy, S. T., \& Wilensky, U. (2008). Inventing a "mid level" to make ends meet: Reasoning between the levels of complexity. Cognition and Instruction, 26(1), 1-47.

Lieberman, A. (2000). Networks as learning communities: Shaping the future of teacher development. Journal of Teacher Education, 51(3), 221-227.

Linn, M., Clark, D., \& Slotta, J. (2002). WISE design for knowledge integration. Science Education, 87(4), 517-538.

Liu, L., \& Hmelo-Silver, C. (2009). Promoting complex systems learning through the use of conceptual representations in hypermedia. Journal of Research in Science Teaching, 46(9), 1023-1040.

Pavard, B., \& Dugdale, J. (2000). The contribution of complexity theory to the study of socio-technical cooperative systems. In A. A. Minai, D. Braha, \& Y. Bar-Yam (Eds.), Unifying themes in complex systems (pp. 39-48). Berlin: Springer.

Penuel, W. R., Fishman, B. J., Cheng, B. H., \& Sabelli, N. (2011). Organizing research and development at the intersection of learning, implementation, and design. Educational Researcher, 40(7), 331-337.

Perkins, D. N., \& Grotzer, T. A. (2005). Dimensions of causal understanding: The role of complex causal models in students' understanding of science. Studies in Science Education, 41, 117-166.

Prime, G., \& Miranda, R. (2006). Urban public high school teachers' beliefs about science learner characteristics: Implications for curriculum. Urban Education, 41(5), 506-532.

Randler, C., \& Bogner, F. X. (2009). Efficacy of two different instructional methods involving complex ecological content. International Journal of Science and Mathematics Education, 7, 315-337.

Reiser, B. J., Tabak, I., Sandoval, W. A., Smith, B., Steinmuller, F., \& Leone, T. J. (2001). BGuILE: Strategic and conceptual scaffolds for scientific inquiry in biology classrooms. In S. M. Carver \& D. Klahr (Eds.), Cognition and instruction: Twenty five years of progress (pp. 263-305). Mahwah, NJ: Erlbaum.

Resnick, M. (1994). Turtles, termites, and traffic jams. Cambridge, MA: MIT Press.

Roque, R. V. (2007). OpenBlocks: An extendable framework for graphical block programming systems (Unpublished master's thesis). Cambridge, MA: Massachusetts Institute of Technology.

Sandoval, W. A., \& Millwood, K. A. (2005). The quality of students' use of evidence in written scientific explanations. Cognition and Instruction, 23(1), 23-55.

Schnotz, W., \& Lowe, R. (2008). A unified view of learning from animated and static graphics. In R. Lowe \& W. Schnotz (Eds.), Learning with animation: Research and design implications (pp. 304-356). New York: Cambridge University Press.

Slotta, J., \& Linn, M. (2009). WISE science: Web-based inquiry in the classroom. New York, NY: Teachers College Press.

Smetana, L. K., \& Bell, R. L. (2012). Computer simulations to support science instruction and learning: A critical review of the literature. International Journal of Science Education, 34(9), 1337-1370.

Soloway, E., \& Pryor, A. (1997). ScienceWare's Model-It: Technology to support authentic science inquiry. The Journal, 25(3), 54-57.

Tabak, I., \& Reiser, B. J. (2008). Software-realized inquiry support for cultivating a disciplinary stance. Pragmatics \& Cognition, 16(2), 307-355.

The National Academies. (2009). Keck futures initiative: Complex systems: Task group summaries. Washington, DC: The National Academies Press.

Varma, K., Husic, F., \& Linn, M. (2008). Targeted support for using technology-enhanced science inquiry modules. Journal of Science Education and Technology, 17, 341-356. 
Wilensky, U., \& Reisman, K. (2006). Thinking like a wolf, a sheep, or a firefly: Learning biology through constructing and testing computational theories-an embodied modeling approach. Cognition and Instruction, 24(2), 171-209.

Wilson, S. M. (2013). Professional development for science teachers. Science, 340, 310-313.

Yoon, S. (2008). An evolutionary approach to harnessing complex systems thinking in the science and technology classroom. International Journal of Science Education, 30(1), 1-32.

Yoon, S. A. (2011). Using social network graphs as visualization tools to influence peer selection decisionmaking strategies to access information about complex socioscientific issues. Journal of the Learning Sciences, 20(4), 549-588.

Yoon, S., \& Klopfer, E. (2006). Feedback (F) fueling adaptation (A) network growth (N) and self-organization (S): A complex systems design and evaluation approach to professional development. Journal of Science Education and Technology, 15(5-6), 353-366.

Yoon, S., Klopfer, E., Wang, J., Sheldon, J., Wendel, D., Schoenfeld, I., et al. (2013). Designing to improve biology understanding through complex systems in high school classrooms: No simple matter! In the proceedings of the. Madison, WI: Computer Supported Collaborative Learning. 